\title{
A INTER-RELAÇÃO DA CONCORDÂNCIA NOMINAL E DA CONCORDÂNCIA NOS PREDICATIVOS/PARTICÍPIOS PASSIVOS, SOB O ENFOQUE DA TEORIA DA VARIAÇÃO E MUDANÇA LINGÜÍSTICA
}

\author{
Juçá Fialho Vazzata Dias \\ Marisa Fernandes
}

\begin{abstract}
RESUMO: This paper intends to examine the relationship between nominal agreement and number agreement in predicative/participle passive, according to Fernandes (1996) and Vazzata-Dias (1996), respectively. In this study, we analyse the speech of residents of Florianópolis, investigating two linguistic variables, Formal Paralelism and Phonic Salience, in order to verify, respectively, the hipothesis that plural markers promote plural markers and zero plural markers promote zero plural markers and that regular plural, because are least distinctive, have lowest probability of agreement. We also investigate three social variables (Sex, age and level of education) in order to verify mainly some indication of stable variation or linguistic change in progress. The research is conducted throughout using the theorical principle of the theory of linguistic variation (Weinreich, Labov \& Herzog, 1968, Labov, 1972 and 1994). For quantitative data processing, we used the VARBRUL programs, version 1988/1992.
\end{abstract}

PALAVRAS-CHAVE: concordância, variação, paralelismo formal, saliência fônica, mudança.

\section{INTRODUÇÃO}

A Sociolingüística laboviana, partindo do princípio de que a língua falada é heterogênea e instável, repisa os caminhos traçados por lingüistas que

Juçá Fialho Vazzata Dias e Marisa Fernandes são doutorandas do Programa de Pós-graduação em Lingüística da UFSC. 
propugnaram a necessidade de se estudar a língua sem dissociá-la da estrutura social, vendo-a não como um sistema abstrato e homogêneo.

Além de sistematizar o conceito de heterogeneidade lingüística, através da idéia de que há variação na fala, a Sociolingüística sistematiza também o conceito de mudança lingüística em progresso, associando, intimamente, fatores lingüísticos e sociais.

É pautado nesses princípios da Sociolingüística (variação e mudança) que desenvolvemos este estudo, o qual consiste na análise dos fenômenos da concordância de número no sintagma nominal e da concordância de número nos predicativos e particípios passivos (FERNANDES,1996 e VAZZATA-DIAS,1996, respectivamente).

Neste trabalho, procuramos estabelecer inter-relações entre as duas análises, para verificar até que ponto os dois fenômenos lingüísticos se afastam ou se aproximam, considerando duas variáveis lingüísticas investigadas em comum o Paralelismo Formal (marcas precedentes) e a Saliência Fônica - e três variáveis sociais - sexo, faixa etária e níveis de escolarização - que também foram consideradas por ambas as autoras. Além disso, pretendemos verificar ainda, através das variáveis sociais faixa etária (principalmente), níveis de escolarização e sexo, se há indícios de variação estável ou de mudança lingüística em progresso envolvendo os dois fenômenos aqui analisados.

\section{OBJETO DE ESTUDO}

A concordância de número em português realiza-se de duas formas: verbal, ocorrendo entre o sintagma nominal sujeito e o verbo, e nominal, ocorrendo entre os elementos flexionáveis do sintagma nominal ou entre o sujeito e o predicativo.

Neste trabalho, estudamos a concordância de número entre os elementos flexionáveis do SN (doravante concordância nominal) e a concordância entre o sujeito e o predicativo (doravante concordância nos predicativos e particípios passivos), partindo do princípio de que cada elemento constitui um dado de análise, cuja marca formal é caracterizada pelo acréscimo do morfema plural/S/.

\section{CONCORDÂNCIA NOMINAL}

- "Ganhava livros todos os anos." (FloFBG) ${ }^{1}$

- "Eu não aguentei passá dos trêys dia." (FloFAG)

- "O meu pai trabalhô esses ano todo." (FloMBC)

- "Eu fiquei lé um ano e trêys meses." (FloFBG)

\footnotetext{
1 - Flo (Florianópolis); F ou M (feminino/masculino); J, A ou B (informantes de 15-20 anos, 25-49 anos, mais de 50 anos, respectivamente); P, G ou C (primário, ginasial ou colegial) 116
} 


\section{CONCORDÂNCIA NOS PREDICATIVOS E PARTICÍPIOS PASSIVOS}

- "eles eru muito bons pra mim" (FloMAP)

- "nóys somos casado" (FloFAG)

- "dois foru criado ali" (FloFAP)

- "meus pais eru bem religioso" (FloMAG)

\section{METODOLOGIA}

Nesta pesquisa, adotamos os princípios metodológicos da Teoria Variacionista Laboviana, cujos objetivos são "estabelecer, via procedimento estatístico-quantitativo, a gramática [da comunidade de fala]" (TARALLO, 1995, apud VAZZATA-DIAS, 1996, p.22). De uma maneira geral, a metodologia laboviana pressupõe variantes a serem estudadas, coleta e codificação dos dados.

Os dois estudos utilizaram o Pacote Computacional VARBRUL $2 \mathrm{~S}$ (desenvolvido por Susan Pintzuk) para a análise estatística dos dados. Tomamos por base a aplicação da regra, ou seja, a presença de marca formal de plural. Portanto, os resultados estatísticos que seguirão devem ser lidos nesse sentido.

\section{Constituição da amostra}

Os dados para este estudo foram retirados do Banco de Dados do Projeto VARSUL (Variação Lingüística Urbana da Região Sul).

CONCORDÂNCIA NOMINAL: Trabalhamos com 30 minutos da fala de 36 informantes florianopolitanos (etnia açoriana) divididos em 12 informantes de 15 20 anos, 12 informantes de 25 - 49 anos e 12 informantes de mais de 50 anos, levando em consideração o sexo (masculino e feminino) e os níveis de escolarização (primário, ginasial e colegial). No total foram ouvidas 18 horas de fala e foram analisados 2.243 dados.

CONCORDÂNCIA NOS PREDICATIVOS E PARTICÍPIOS PASSIVOS:

Coletamos todos os dados encontrados em 1 hora de fala de 36 informantes de Florianópolis (açorianos) divididos em: 12 informantes de 15 - 20 anos, 12 informantes de 25 - 49 anos e 12 informantes de mais de 50 anos, também considerando o sexo (masculino e feminino) e os níveis de escolarização (primário, ginasial e colegial). Obtivemos um total de 36 horas de fala e foram analisados 358 dados.

\section{ANÁLISE DAS VARIÁVEIS LINGÜÍSTICAS}

Como especificamos na introdução deste estudo, um dos nossos objetivos é correlacionar a concordância de número no sintagma nominal e a concordância nos predicativos e particípios passivos. Por este motivo, iremos abordar apenas duas variáveis lingüísticas: paralelismo formal e saliência fônica. Optamos por 
estas variáveis por terem sido tratadas nos dois estudos de modo praticamente uniforme.

\section{Paralelismo formal}

O princípio da economia lingüística vem sendo evocado para explicar fenômenos que envolvem variação na concordância (cf. HAIMAN, 1983, apud SCHERRE, 1988, p.48). Segundo este princípio, quanto mais previsível a informação, menos codificação ela requer.

Todavia, estudos recentes não corroboram este princípio. O que vemos, portanto, é que "uma marca imediatamente precedente leva a mais marcas (...) e zeros levam a zeros" (POPLACK, 1981, apud SCHERRE, 1988, p.168). Ou seja, há uma tendência geral para formas gramaticais particulares ocorrerem juntas (SCHIFFRIN, 1981, apud SCHERRE, 1988, p.283).

Na concordância nominal, Scherre (1988) e Fernandes (1996) dividiram a variável paralelismo formal (marcas precedentes) em sete fatores, observando se nos elementos anteriores ao elemento analisado havia, ou não, a marca formal de plural.

Na concordância nos predicativos e particípios passivos, Scherre (1991) e Vazzata-Dias (1996) subdividiram esta variável em cinco fatores, também levando em consideração a presença/ausência de marca no elemento anterior ao elemento analisado.

Vejamos como a variável foi trabalhada em ambos os fenômenos.

\section{CONCORDÂNCIA NOMINAL}

1. Numerais precedentes terminados em S na primeira posição - Ex. "tinhu dois filhinhos" (FloFJC)

2. Numerais precedentes não terminados em $\mathrm{S}$ na primeira posição - Ex. "Tenho quinze subrinho." (FloFJP)

3. Presença de marca formal na primeira posição - Ex. "Tenho grandes habilidade." (FloMJC)

Obs.: Nos fatores relacionados acima, os itens analisados encontram-se na segunda posição

4. Zero na primeira posição - Ex.: "Quando eu tinha o meus vinte ano, dezoito." (FloFBG)

5. Presença de marca formal a partir da primeira posição (SS-) - Ex. "Os gêneros alimenticios" (FloFBG)

6. Mistura de marcas com marca formal precedendo (OS-) - Ex. "Vai eu e o meus amigos." (FloMJC)

7. Mistura de marcas com zero precedendo ( $\mathrm{S} 0$-) - Ex. "dos guri piqueno, né?" (FloFJP)

Obs.: Os itens analisados encontram-se na terceira posição. 


\section{CONCORDÂNCIA NOS PREDICATIVOS E PARTICÍPIOS PASSIVOS}

1. Predicativo particípio em construção isolada - Ex. Os dois andares de baixo são comerciais." (FloMJC)

2. Primeiro de uma série - Ex. "as pessoas são muito egoístas...0 são tão egoístas." (FloFJC)

3. Predicativo/particípio precedido de predicativo/particípio com todas as marcas de plural (SS) - Ex. "as pessoas são muito egoístas... 0 são tão egoístas." (FloFJC)

4. Predicativo/particípio precedido de predicativo/particípio sem marcas de plural $(00)$ - Ex. Os bailes era bom... os baile era rodiado de janela." (FloFAP)

Como resultados, obtivemos:

Concordância em relação ao paralelismo formal (Florianópolis, VARSUL)

\begin{tabular}{|c|c|c|c|c|c|}
\hline \multicolumn{3}{|c|}{ CONC. NOMINAL } & \multicolumn{3}{|c|}{ CONC. PRED/PARTICÍPIOS PASSIVOS } \\
\hline & Apl./total = \% & P.Rel. & & Apl./total = \% & P.Rel. \\
\hline 1) Zero & $44 / 44=100 \%$ & - & 1) Isolado & $93 / 272=34 \%$ & 0,50 \\
\hline 2) NS & $133 / 178=63 \%$ & 0,60 & 2) 10. série & $13 / 37=35 \%$ & 0,53 \\
\hline 3) $\mathrm{N} \mathrm{s} / \mathrm{S}$ & $130 / 200=65 \%$ & 0,65 & 3) SS- & $13 / 18=72 \%$ & 0,77 \\
\hline 4) S- & $367 / 774=47 \%$ & 0,44 & 4) 00 - & $6 / 13=19 \%$ & 0,32 \\
\hline 5) SS- & $39 / 58=67 \%$ & 0,74 & & & \\
\hline 6) $0 \mathrm{~S}-$ & $47 / 88=53 \%$ & 0,66 & & & \\
\hline 7) S0- & $1 / 40=2 \%$ & 0,03 & & & \\
\hline TOTAL & $741=1.382=54 \%$ & & & $125 / 358=35 \%$ & \\
\hline
\end{tabular}

$\mathrm{Na}$ concordância nominal, o fator zero na primeira posição é o que mais favorece marcas no segundo elemento (100\%), pois, como não há marca formal na primeira posição, o segundo elemento tende a ser marcado; caso contrário, corre-se o risco de perder a informação de plural. Nos numerais terminados em S (NS-), numerais não terminados em $\mathrm{S}(\mathrm{N} \mathrm{s} / \mathrm{S}-)$ e presença de marcas na primeira posição (S-), em que a posição de análise é o segundo elemento, vemos que os numerais favorecem mais a presença de marcas do que outras marcas na primeira posição. Scherre (1988, p.173), "numa linha funcionalista kiparskiana, considera que o numeral favorece mais marcas nos dados dos falantes semi-escolarizados, porque ele tem apenas marca semântica de pluralidade (...)", fato este que podemos comprovar também em nosso estudo. Em relação aos fatores presença de marcas a partir da primeira posição (SS-) e mistura de marcas (0S- e S0-), podemos perceber nitidamente que a presença de marcas anterior ao elemento analisado favorece mais marcas no elemento seguinte.

$\mathrm{Na}$ concordância nos predicativos e particípios passivos, o mesmo princípio se repete, ou seja, a presença de marcas leva a mais marcas. O fator predicativo/particípio precedido de predicativo/particípio com todas as marcas de plural apresenta maior peso relativo de presença do morfema de plural $(0,77)$, enquanto que o fator predicativo/particípio precedido de predicativo/particípio sem marcas de plural apresenta apenas 0,32 de peso relativo, corroborando, dessa 
forma, o Princípio do Processamento Paralelo. Comparando os resultados dos dois estudos podemos perceber nitidamente que marcas levam a marcas e zeros levam a zeros $^{2}$.

\section{Saliência Fônica e Tonicidade}

Os primeiros estudos visando a saliência fônica, no Brasil, foram feitos por Lemle e Naro (1974-1976, apud FERNANDES, 1996) em pesquisa sobre concordância verbal. Na época, os autores acima citados concluíram que as formas mais salientes, por serem mais perceptíveis, são mais marcadas.

Este tema foi retomado nos estudos da concordância nominal e concordância nos predicativos de forma homogênea, sendo subdividido da seguinte maneira:

1) Itens terminados em $\tilde{A} O$

Ex. "aqueles botões amarelo...” (FloFAC) / “... são muito brigão, né? (FloMJP)

2) Itens terminados em $-\mathrm{L}$

Ex. "faço pratos especiais." (FloFJC) / "eles são bem liberaw" (FloMAG)

3) Itens terminados em -R

Ex. “...era esses moradores” (FloMJG) / “... eles eru menores, né? (FloMJP)

4) Itens terminados em $-\mathrm{S}$

Ex. "fui só duas vezes" (FloMJP) / "esses são capazes." (FloMBG)

5) Plurais duplos (metafônicos)

Ex. "ganhamo trêys jogos" (FloMJA) / “...eram bem religioso.” (FloMAG)

6) Regulares

Ex. "dos guri pequeno, né?” (FloFJP) / “... era tudo cortado.” (FloMAP)

$\mathrm{Na}$ análise desta variável, fizemos um cruzamento entre saliência fônica e tonicidade dos itens lexicais. Os resultados encontram-se na Fig. 2, abaixo.

Concordância em relação a saliência fônica e tonicidade (Florianópolis, VARSUL)

\begin{tabular}{|l|c|c|c|c|}
\hline & \multicolumn{2}{|c|}{ CONC. NOMINAL } & \multicolumn{2}{c|}{ CONC. NOS PRED / PARTICIPIOS PASSIVOS } \\
\hline FATORES & Apl./total $=\%$ & P.Rel. & Apl./total = \% & P.Rel. \\
\hline Itens em ÃO & $23 / 26=88 \%$ & 0,89 & $0 / 4=0$ & - \\
\hline Itens em -L & $11 / 18=61 \%$ & 0,72 & $9 / 16=57$ & 0,78 \\
\hline Itens em -R & $39 / 52=75 \%$ & 0,76 & $6 / 14=43$ & 0,61 \\
\hline Itens em -S & $41 / 53=77 \%$ & 0,73 & $0 / 2=0$ & - \\
\hline Duplos oxítonos & $4 / 6=67 \%$ & 0,68 & - & - \\
\hline Duplos paroxítonos & $8 / 11=73 \%$ & 0,76 & $3 / 11=27$ & 0,40 \\
\hline Reg. Oxítonos & $65 / 104=63 \%$ & 0,64 & $6 / 19=32$ & 0,49 \\
\hline Reg. Paroxítonos & $1340 / 1933=69 \%$ & 0,47 & $93 / 271=34$ & 0,48 \\
\hline Reg. Proparoxítonos & $20 / 39=51 \%$ & 0,39 & $8 / 21=38$ & 0,53 \\
\hline
\end{tabular}

Fig.2

\footnotetext{
${ }^{2}$ Apesar de termos, na concordância nominal, o paralelismo atuando intra-setencial e, na concordância nos predicativos/particípios passivos, extra-sentencialmente (o que em termos de processamento precisa ser considerado), o que queremos mostrar é que o Princípio do Processamento Paralelo é evidente nos dois fenômenos, ressalvada, é claro, a questão posta acima.
} 
Como podemos perceber, na concordância nominal os itens mais salientes realmente favorecem mais marcas de plural que os itens menos salientes. Isso se aplica também aos itens regulares, onde os regulares oxítonos retêm mais marcas que os regulares paroxítonos e proparoxítonos.

$\mathrm{Na}$ concordância nos predicativos e particípios passivos, os itens terminados em $\tilde{A} O$ e os itens terminados em $\mathrm{S}$ não favoreceram a presença da marca formal de plural; acreditamos que tal fato deva-se à pequena quantidade de dados ( 4 e 2, respectivamente). Já os itens terminados em -L e os itens terminados em $-\mathrm{R}$ foram mais marcados que os itens regulares. Apesar da diferença entre os duplos paroxítonos e os regulares proparoxítonos nos dois fenômenos em análise, evidenciando que, quanto maior a diferença material fônica na relação singular/plural, maior é a presença de marca formal de plural. Conforme verificamos, em ambos os estudos vemos que o princípio da saliência fônica, proposto por Lemle e Naro, se aplica: os itens mais salientes, por serem mais perceptíveis, são mais marcados.

\section{ANÁLISE DAS VARIÁVEIS SOCIAIS}

As variáveis sociais têm demonstrado uma significativa importância na maior parte dos estudos variacionistas, dentre elas, faixa etária, sexo, formação escolar, nível socioeconômico, mercado ocupacional, origem geográfica, sensibilidade lingüística e contato com a mídia, etc. têm sido as variáveis mais recorrentes nos trabalhos variacionistas. Neste estudo, consideramos as variáveis sexo, idade e escolaridade, que são, ao lado da variável etnia, as controladas pelo Projeto VARSUL.

Como um dos objetivos deste trabalho é tentar verificar se há mudança em curso ou, ao contrário, variação estável nos fenômenos aqui considerados, apresentamos, primeiramente, as variáveis sociais isoladas. Numa segunda etapa, iremos cruzar todas as variáveis extra-lingüísticas. Antes, porém, faremos algumas breves considerações acerca da mudança lingüística.

Empiricamente, constatamos que as línguas humanas mudam com o passar do tempo, apesar de que nós, enquanto falantes, normalmente não temos consciência de tal fato. A imagem que construímos da nossa língua é baseada muito mais na sensação de permanência, de estaticidade do que na sensação de mudança, o que não é gratuito, afinal as mudanças lingüísticas podem ser bastante lentas, sendo, algumas delas, pouco prováveis de serem observadas no nosso dia-adia.

Contudo, há situações em que acabamos observando a existência de mudanças. Isso se dá, por exemplo, quando somos expostos a textos muito antigos escritos em nossa língua; ou quando convivemos com falantes bem mais jovens ou bem mais velhos; ou, ainda, quando interagimos com falantes de classes sociais excluídas ou que têm pouco acesso à escola e à cultura escrita. 
Na história de uma língua, as mudanças podem se dar nos níveis fonéticofonológico, morfológico, sintático, semântico, lexical e pragmático, e são caracterizadas como contínuas ou como graduais, no sentido em que não acontecem abruptamente e de forma global e integral mas, ao contrário, dão-se de forma gradativa, atingindo partes da língua e nunca o seu todo. Assim, uma forma $x$ não passa diretamente a uma forma $y$ sem que de um extremo a outro não ocorram elementos intermediários; e, nesse processo, há um período de tempo em que ambas as formas coexistem como variantes, podendo ocorrer uma disputa entre as mesmas, acabando por uma forma sobrepujando a outra e se implementando, ou, diferentemente, ambas as formas convivendo pacificamente por um longo tempo.

Segundo Labov (1994), os estudos de mudança lingüística em progresso têm demonstrado que não é só por meio da separação geográfica que a divergência lingüística se dá. Pessoas que vivem nas mesmas cidades, freqüentam as mesmas escolas, e são expostas aos mesmos meios de comunicação podem apresentar formas lingüísticas consideravelmente diferentes, à medida que podem ser afetadas por mudanças lingüísticas de formas também bastante diferentes.

Quando falamos em mudança lingüística, fatalmente nos vêm à mente perguntas do tipo: a mudança lingüística pode ser de fato observada? e a mudança lingüística em progresso? o que significa observar o estado de uma língua?

Para tratar dessas questões acerca da mudança lingüística em progresso, a Sociolingüística Variacionista lança mão de duas abordagens, a saber: mudança em tempo aparente e mudança em tempo real.

A observação em tempo aparente consiste em uma abordagem bastante atraente para o lingüista que pretende analisar a mudança lingüística. Tal abordagem trabalha com a distribuição de variáveis lingüísticas por níveis de idade, sendo que o trabalho do pesquisador é analisar se os resultados estão realmente apontando para uma possível mudança em progresso, ou se se está diante de um caso de pura gradação etária.

Conforme Labov (1994), uma indicação de que uma provável mudança lingüística esteja em progresso pode ser observada pelos resultados quantitativos, através da elevação e queda dos coeficientes de idade, formando um gráfico cujo desenho é uma curva em S. Dessa forma, o que teríamos seria uma mudança que começa em uma taxa lenta, progride rapidamente no meio do trajeto, e cai vagarosamente em seus últimos estágios.

Dada uma clara distribuição etária em tempo aparente, fica-nos a questão: estaria isto indicando realmente uma mudança em progresso? Para solucionar essa problemática, o pesquisador pode recorrer à abordagem da observação em tempo real, o que lhe daria maiores garantias de que se está diante de um caso de mudança lingüística, ressalvadas as sérias e inesperadas dificuldades que, possivelmente, o lingüista irá enfrentar.

Há, basicamente, duas maneiras de se lidar com essa abordagem. A primeira, mais simples e eficiente, é a pesquisa à literatura para se comparar dados atuais com os mais remotos. A segunda, muito mais trabalhosa e elaborada, 
consiste em se retornar à comunidade após alguns anos e repetir o mesmo estudo. Nesse segundo caso, o pesquisador pode desenvolver o que Labov (1994) denomina de Trend Studies (pesquisa-se o mesmo número de pessoas, distribui-se a amostragem da mesma forma, obtém-se os dados e analisa-se da mesma maneira, só que x anos mais tarde); ou Panel Studies (tenta-se localizar os mesmos indivíduos que serviram de informantes do primeiro estudo, e monitoriza-se qualquer mudança em seus comportamentos, submetendo-os ao mesmo questionário, entrevista, ou experimento) ${ }^{3}$.

O exemplo clássico de observação da mudança lingüística em tempo real é o estudo desenvolvido por Hermann em 1929, numa pequena aldeia Suíça chamada Charmey. Vinte e cinco anos depois que Gauchat detectou mudanças em tempo aparente para cinco variáveis lingüísticas (LABOV, 1994), Hermann verificou que o mesmo estava correto em suas previsões, pois de fato as tais mudanças (referentes às cinco variáveis) já estavam completas ou em vias de se completarem.

Em vista do que apresentamos, fica bastante clara a importância que reveste ambas as abordagens aqui discutidas; e uma coisa parece evidente: respeitadas as particularidades de cada uma das duas, é com a combinação de observações em tempo aparente e observações em tempo real que teremos estudos mais efetivos sobre mudança lingüística.

\section{Faixa etária}

Como mencionamos anteriormente, trataremos de cada variável social isoladamente, começando pelo fator faixa etária.

Na Fig. 3, apresentamos os resultados referentes a esse fator.

Concordância em relação a faixa etária (Florianópolis, VARSUL)

\begin{tabular}{|c|c|c|c|c|}
\hline & \multicolumn{2}{|c|}{ CONCORDÂNCIA NOMINAL } & CONC. NOS PRED/PARTICÍPIOS PASSIVOS \\
\hline Faixa Etária & Apl./Total $=\%$ & P.Rel. & Apl./Total $=\%$ & P.Rel. \\
\hline $15-21$ anos & $699 / 992=70 \%$ & 0,51 & $36 / 111=32 \%$ & 0,47 \\
\hline $25-49$ anos & $426 / 627=68 \%$ & 0,49 & $39 / 125=31 \%$ & 0,46 \\
\hline Mais de 50 anos & $427 / 624=68 \%$ & 0,49 & $50 / 122=41 \%$ & 0,57 \\
\hline TOTAL & $1552 / 2243=69 \%$ & & $125 / 358=35 \%$ & \\
\hline
\end{tabular}

Fig.3

Segundo os resultados acima, não percebemos nenhum indício de que esteja ocorrendo alguma mudança lingüística em progresso, na concordância nominal. Esta variável, inclusive, não foi selecionada como estatisticamente relevante.

${ }^{3}$ Um Panel Study completo foi realizado em Montreal em 1984, baseado na amostragem de 120 informantes no estudo de Sankoff-Cedergren. 
Na concordância nos predicativos e particípios passivos, percebemos que há um aumento de marcas nos informantes mais velhos, mas também não tão relevante para que pudéssemos falar em mudança.

Comparando os dois estudos, percebemos que eles muito se assemelham, com um leve aumento de marcas na concordância nos predicativos e particípios passivos com os informantes de mais de 50 anos, como podemos ver no gráfico abaixo. Conforme vimos no item Mudança Lingüistica, para se ter caracterizado um possível quadro de mudança em tempo aparente, precisaríamos obter uma curva em $S$, o que não é o caso. O que temos, então, é uma distribuição plana, dando indícios de uma variação estável envolvendo os dois fenômenos.

Concordância em relação a faixa etária (Florianópolis, VARSUL)

IDADE

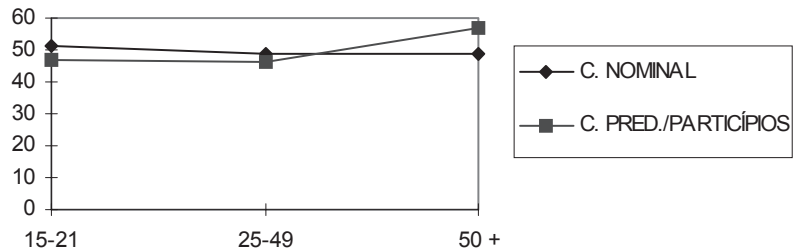

Fig.4

\section{Níveis de escolarização}

Esta é provavelmente uma das variáveis sociais mais significativas na maioria dos estudos variacionistas. No nosso estudo, a escolarização foi a primeira variável social escolhida como estatisticamente relevante, como podemos ver na tabela seguinte.

Concordância em relação a níveis de escolarização (Florianópolis, VARSUL)

\begin{tabular}{|l|c|c|c|c|}
\hline & \multicolumn{2}{|c|}{ CONC. NOMINAL } & \multicolumn{2}{c|}{ CONC. PRED/ PARTICÍPIOS PASSIVOS } \\
\hline ESCOLARIZAÇÃO & Apl./Total $=\%$ & P.Rel. & Apl./Total $=\%$ & P.Rel. \\
\hline PRIMÁRIO & $456 / 774=59 \%$ & 0,35 & $21 / 134=16 \%$ & 0,28 \\
\hline GINASIAL & $521 / 726=72 \%$ & 0,54 & $43 / 114=38 \%$ & 0,57 \\
\hline COLEGIAL & $575 / 743=77 \%$ & 0,63 & $61 / 110=55 \%$ & 0,70 \\
\hline TOTAL & $1552 / 2243=69 \%$ & & $125 / 358=35 \%$ & \\
\hline
\end{tabular}

Tanto na concordância nominal quanto na concordância nos predicativos e particípios passivos, o papel da escola é fundamental na regra de concordância, ou seja, o aumento da marca formal de plural é proporcional ao aumento dos anos de escolarização. 
Confrontando os dois estudos, obtemos o Gráfico da Fig.6.

Concordância em relação a níveis de escolarização (Florianópolis, VARSUL)

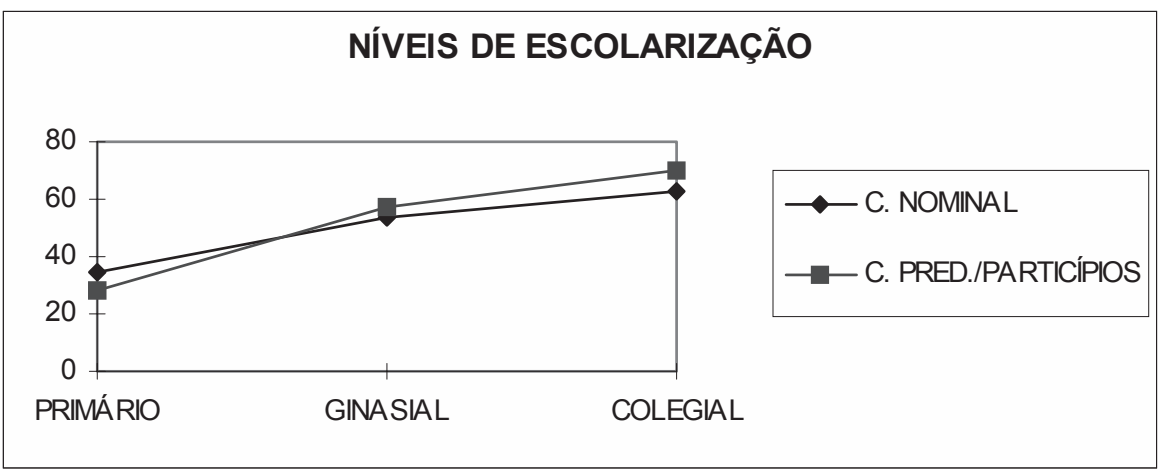

Fig.6

Sexo

Outra variável bastante discutida nos fenômenos de mudança lingüística ou variação estável é sexo. E, em ambos os fenômenos, a conclusão é a mesma: as mulheres são mais sensíveis às formas lingüísticas de prestígio ${ }^{4}$. Agora, no que tange ao fenômeno de mudança lingüística, tradicionalmente, vários trabalhos têm apontado a atuação da mulher quando a forma é prestigiada. Mas, quando a forma é desprestigiada, cabe ao homem o papel da mudança lingüística, mostrando uma atitude conservadora por parte das mulheres. (PAIVA, 1991, apud FERNANDES,1996, p.101)

Vejamos, na Fig. 7, os resultados deste estudo.

Concordância em relação a sexo (Florianópolis, VARSUL)

\begin{tabular}{|c|c|c|c|c|}
\hline & \multicolumn{2}{|c|}{ CONC. NOMINAL } & \multicolumn{2}{c|}{ CONC. PRED/PARTICÍPIOS PASSIVOS } \\
\hline SEXO & Apl./Total $=\%$ & P.Rel. & Apl./Total $=\%$ & P.Rel. \\
\hline FEMININO & $900 / 1288=70 \%$ & 0,51 & $92 / 223=41 \%$ & 0,58 \\
\hline MASCULINO & $652 / 955=68 \%$ & 0,49 & $33 / 135=24 \%$ & 0,37 \\
\hline TOTAL & $1552 / 2243=69 \%$ & & $125 / 358=35 \%$ & \\
\hline
\end{tabular}

Fig.7

$\mathrm{Na}$ concordância nominal, poderíamos dizer que a diferença é quase insignificante em relação aos dois sexos. Já na concordância nos predicativos e particípios passivos, há um aumento de marcas de concordância, liderado pelas mulheres $(0,58)$, enquanto os homens apresentam apenas 0,37 de concordância.

${ }^{4}$ Obviamente, temos que considerar que os resultados mais fidedignos aparecem quando cruzamos os fatores sociais. Nesse sentido, confira Scherre (1988), Fernandes (1996), Vazzata-Dias (1996, a sair). 
Chambers (1995, apud VAZZATA-DIAS, 1996, p.88 ), ao citar outros estudiosos do assunto, diz que:

(...) as mulheres, mais do que os homens, demonstram uma sensibilidade maior a traços lingüísticos socialmente avaliados. (WOLFRAM, 1969).

As mulheres demonstram mais consciência das normas de prestígio tanto em suas falas quanto em suas atitudes com relação à fala. (WOLFRAM \& FASOLD, 1974). As mulheres (...) são claramente mais preocupadas com a pressão exercida por normas locais e mais preocupadas em asseverar seu status de acordo com (...) a estrutura social. (ROMAINE, 1978).

Os resultados com relação ao fator sexo demonstram que ambos os fenômenos lingüísticos parecem estar passando por um processo de variação estável, uma vez que são as mulheres (as mais conservadoras, lingüisticamente falando) que mais estão mantendo a marca de prestígio.

Na Fig.8, visualizamos os resultados para a variável sexo nos dois tipos de concordância no sintagma nominal.

Concordância em relação a idade e níveis de escolarização (Florianópolis, VARSUL)

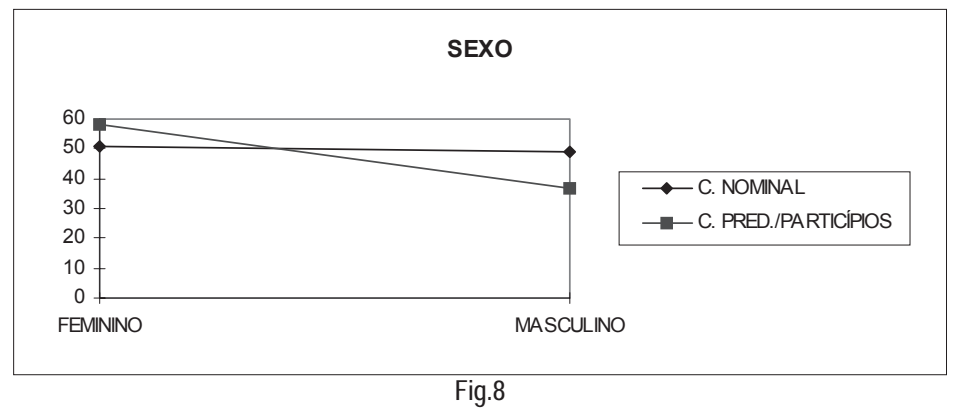

\section{CRUZAMENTO DAS VARIÁVEIS SOCIAIS}

\section{Idade e níveis de escolarização}

Nas Figuras 9 e 10 mostramos os resultados referentes a este cruzamento.

Concordância em relação a faixa etária e níveis de escolarização (Florianópolis, VARSUL)

\begin{tabular}{|c|c|c|c|c|c|c|}
\hline \multicolumn{7}{|c|}{ CONCORDÂNCIA NOMINAL } \\
\hline & \multicolumn{2}{|c|}{ Primário } & \multicolumn{2}{c|}{ Ginasial } & \multicolumn{2}{c|}{ Colegial } \\
\hline $15-21$ & $175 / 342=51 \%$ & 0,23 & $240 / 316=76 \%$ & 0,59 & $284 / 334=85 \%$ & 0,75 \\
\hline $25-49$ & $153 / 217=71 \%$ & 0,55 & $129 / 198=65 \%$ & 0,44 & $144 / 212=68 \%$ & 0,43 \\
\hline+50 & $128 / 215=60 \%$ & 0,35 & $152 / 212=72 \%$ & 0,50 & $147 / 197=75 \%$ & 0,66 \\
\hline
\end{tabular}

126 
Os resultados acima nos mostram que, em relação aos informantes de 1521 anos e os informantes de mais de 50 anos, o aumento de marcas de plural é proporcional ao aumento dos anos de escolarização. $\mathrm{O}$ mesmo não ocorre na faixa etária de 25-49 anos. Se olharmos em relação aos anos de escolarização, percebemos que no nível primário são os informantes de 25-49 anos que mais fazem concordância, já nos níveis ginasial e colegial, são os informantes mais novos que lideram a concordância.

Concordância em relação a faixa etária e níveis de escolarização (Florianópolis, VARSUL)

\begin{tabular}{|c|c|c|c|c|c|c|}
\hline \multicolumn{7}{|c|}{ CONCORDÂNCIA NOS PREDICATIVOS E PARTICÍPIOS PASSIVOS } \\
\hline & \multicolumn{2}{|c|}{ Primário } & \multicolumn{2}{c|}{ Ginasial } & \multicolumn{2}{c|}{ Colegial } \\
\hline $15-21$ & $2 / 50=4 \%$ & 0,07 & $21 / 38=55 \%$ & 0,75 & $13 / 23=57 \%$ & 0,71 \\
\hline $25-49$ & $14 / 44=32 \%$ & 0,57 & $16 / 47=34 \%$ & 0,58 & $9 / 34=26 \%$ & 0,48 \\
\hline+50 & $5 / 40=13 \%$ & 0,23 & $6 / 29=21 \%$ & 0,37 & $39 / 53=71 \%$ & 0,87 \\
\hline
\end{tabular}

Fig.10

Podemos perceber que também não há uma homogeneidade no que se refere ao fator idade na concordância nos predicativos e particípios passivos. No nível primário, são os informantes de 25-49 anos que lideram a concordância; no nível ginasial, os informantes mais jovens; e no colegial, os informantes com mais de 50 anos concordam mais. Por outro lado, percebemos nitidamente a influência da escolarização no aumento da concordância.

\section{Idade e sexo} cruzamento.

Vejamos as Figuras 11 e 12, onde apresentamos os resultados desse

Concordância em relação a faixa etária e sexo

\begin{tabular}{|c|c|c|c|c|c|c|}
\hline \multicolumn{7}{|c|}{ CONCORDÂNCIA NOMINAL } \\
\hline & \multicolumn{2}{|c|}{$15-21$} & \multicolumn{2}{c|}{$25-49$} & \multicolumn{2}{c|}{ Mais de 50} \\
\hline & Apl./Total $=\%$ & P.Rel. & Apl./Total $=\%$ & P.Rel. & Apl./Total = \% & P.Rel \\
\hline Feminino & $371 / 533=70 \%$ & 0,50 & $287 / 417=69 \%$ & 0,49 & $242 / 338=72 \%$ & 0,56 \\
\hline Masculino & $328 / 459=71 \%$ & 0,51 & $139 / 210=66 \%$ & 0,45 & $185 / 286=65 \%$ & 0,44 \\
\hline
\end{tabular}

Fig.11

Segundo a Fig.11, há uma grande homogeneidade entre os sexos feminino e masculino referentes as idades de 15-21 anos e 25-49 anos. Já com os informantes com mais de 50 anos, há um aumento de concordância com os informantes do sexo feminino, fato este já demonstrado em estudos variacionistas, em que as mulheres são mais conservadoras no que se refere às formas estigmatizadas. 
Concordância em relação a faixa etária e sexo (Florianópolis, VARSUL)

\begin{tabular}{|c|c|c|c|c|c|c|}
\hline \multicolumn{7}{|c|}{ CONCORDÂNCIA NOS PREDICATIVOS E PARTICÍPIOS PASSIVOS } \\
\hline & \multicolumn{2}{|c|}{$15-21$} & \multicolumn{2}{c|}{$25-49$} & \multicolumn{2}{c|}{ Mais de 50} \\
\hline & Apl./Total $=\%$ & P.Rel. & Apl./Total $=\%$ & P.Rel. & Apl./Total = \% & P.Rel \\
\hline Feminino & $28 / 71=39 \%$ & 0,53 & $20 / 67=30 \%$ & 0,43 & $44 / 85=52 \%$ & 0,59 \\
\hline Masculino & $8 / 40=20 \%$ & 0,43 & $19 / 58=33 \%$ & 0,56 & $6 / 37=16 \%$ & 0,34 \\
\hline
\end{tabular}

Fig.12

Com relação à concordância nos predicativos e particípios passivos, vemos que as mulheres lideram a concordância nas faixas etárias de 15-21 anos e mais de 50 anos. No que se refere especificamente às faixas etárias, percebemos que não há uma convergência no aumento/diminuição de concordância com o aumento de idade. Este fato nos leva a crer que talvez não esteja ocorrendo mudança em progresso no que se refere aos estudos da concordância.

Apenas na faixa etária de 25 a 49 anos os homens lideram a manutenção da regra de concordância; nas demais faixas etárias, vemos novamente as mulheres fazendo mais uso da concordância.

\section{Níveis de escolarização e sexo}

Vejamos os resultados alcançados nesse cruzamento (Figuras 13 e 14)

Concordância em relação a níveis de escolarização e sexo (Florianópolis, VARSUL)

\begin{tabular}{|c|c|c|c|c|c|c|}
\hline \multicolumn{7}{|c|}{ CONCORDÂNCIA NOMINAL } \\
\hline & \multicolumn{2}{|c|}{ Primário } & \multicolumn{2}{|c|}{ Ginasial } & \multicolumn{2}{|c|}{ Colegial } \\
\hline Sexo & Apl./Total = \% & P.Rel. & Apl. $/$ Total = \% & P.Rel. & Apl. $/$ Total $=\%$ & P.Rel \\
\hline Feminino & $256 / 475=54 \%$ & 0,27 & $335 / 431=78 \%$ & 0,63 & $309 / 382=81 \%$ & 0,69 \\
\hline Masculino & $200 / 299=67 \%$ & 0,46 & $186 / 295=63 \%$ & 0,40 & $266 / 361=74 \%$ & 0,57 \\
\hline
\end{tabular}

Fig.13

Se olharmos horizontalmente a Fig.13, podemos perceber que, com o aumento de escolaridade, há também aumento na marca de concordância, tanto no sexo masculino quanto no sexo feminino. No ginasial e no colegial, as mulheres lideram o aumento de concordância, o oposto ocorrendo no nível primário.

Concordância em relação a níveis de escolarização e sexo (Florianópolis, VARSUL)

\begin{tabular}{|c|c|c|c|c|c|c|}
\hline \multicolumn{7}{|c|}{ CONCORDÂNCIA NOS PREDICATIVOS E PARTICÍPIOS PASSIVOS } \\
\hline \multicolumn{2}{|c|}{ Primário } & \multicolumn{2}{c|}{ Ginasial } & \multicolumn{2}{c|}{ Colegial } \\
\hline Sexo & Apl./Total $=\%$ & P.Rel. & Apl./Total $=\%$ & P.Rel. & Apl./Total = \% & P.Rel \\
\hline Feminino & $14 / 87=16 \%$ & 0,29 & $30 / 65=46 \%$ & 0,64 & $48 / 71=68 \%$ & 0,80 \\
\hline Masculino & $7 / 47=15 \%$ & 0,28 & $13 / 49=27 \%$ & 0,45 & $13 / 39=33 \%$ & 0,48 \\
\hline
\end{tabular}

Fig.14 
Segundo a Fig.14, vemos que a concordância, no que se refere ao sexo feminino, aumenta muitíssimo com a elevação do grau de escolarização. E as mulheres fazem mais uso de concordância, em todos os níveis escolares, do que os homens.

Segundo Oliveira e Silva (1993, apud FERNANDES, 1996, p.106), essa tendência a uma melhor resposta das mulheres perante a escolarização é coerente com o que se sabe sobre a socialização na escola. É de conhecimento geral que o papel da escola é diferente entre os rapazes e entre as moças. Enquanto as meninas e moças se orgulham de serem boas alunas e de competir pelos primeiros lugares, (...) entre os meninos essas atitudes são negativas e sujeitas a apelidos e "chacotes" para o menino que a adotar.

\section{CONSIDERAÇÕES FINAIS}

Conforme especificamos na introdução deste trabalho, dois foram os objetivos da presente investigação:

1 - proceder a uma análise das variáveis lingüísticas Paralelismo Formal e Saliência Fônica e das variáveis sociais sexo, faixa etária e grau de escolarização, tentando traçar uma relação entre a concordância nominal e a concordância nos predicativos e particípios passivos;

2 - investigar se os fenômenos lingüísticos em estudo refletem um estágio de variação sociolingüística estável ou um processo de mudança lingüística em progresso.

Sem perdermos de vista dois pontos extremamente pertinentes para a interpretação de nossos resultados (a diferença na quantidade de dados trabalhados na concordância nominal e na concordância nos predicativos e particípios passivos; e a não completa equivalência com relação aos fatores da variável Paralelismo Formal), podemos constatar que, em geral, tanto as variáveis lingüísticas quanto as não lingüísticas se comportam de forma semelhante, mostrando-nos que ambos os fenômenos se aproximam.

Vimos que tanto num fenômeno lingüístico quanto noutro, o Princípio do Processamento Paralelo parece se corroborar, dando-nos a nítida percepção de que marcas levam a marcas e zeros levam a zeros.

Com relação à variável Saliência Fônica, pudemos verificar que ambos os tipos de concordância de número (entre os elementos flexionáveis do SN ou entre o sujeito e o predicado) se aproximam. Comparando os dois fenômenos, vemos que o Princípio da Saliência Fônica, que diz que os itens mais salientes, por serem mais perceptíveis, são mais marcados, se aplica.

No que se refere às variáveis sociais faixa etária, níveis de escolarização e sexo, verificamos que, com relação às duas primeiras, os resultados são consideravelmente próximos; e isto fica mais evidente quando observamos os Gráficos das Figuras 4 e 6 . Já quanto ao fator sexo, a relação não é tão próxima (cf. Fig. 8). 
Em nossa análise, onde comparamos fenômenos lingüísticos que foram analisados por Fernandes (1996) e Vazzata-Dias (1996) separadamente, buscamos também verificar uma possível indicação de mudança lingüística em curso, através da observação em tempo aparente. Nesta etapa do estudo, entretanto, constatamos que ambos os fenômenos se comportam como variação lingüística estável. De qualquer forma, a variação que envolve concordância de número no $\mathrm{SN}$ e nos predicativos/particípios passivos, refletindo ou não processo de mudança lingüística, é inerente, uma vez que a influência das variáveis lingüísticas e sociais se dá de forma bastante consistente.

Como sugestão para dar continuidade ao trabalho que aqui nos propusemos desenvolver, indicamos uma análise mais apurada das variáveis sociais (aumentando o número de faixas etárias, considerando outros fatores sociais como mercado de trabalho, classe social, etc.), além de uma ampliação dos dados, para verificação da possibilidade de mudança em curso.

\section{BIBLIOGRAFIA}

FARACO, Carlos Alberto. Lingüistica histórica. São Paulo, Editora Martins Fontes, 1988.

FERNANDES, Marisa. A concordância nominal na Região Sul. Florianópolis, UFSC, 1996. Dissertação de Mestrado.

LABOV, William. Language in the inner city. Philadelphia, University of Pennsylvania Press, 1972a.

. Sociolinguistic patterns. Philadelphia, University of Pennsylvania Press, 1972b.

_. Principles of linguistic change - internal factors. Cambridge, Blackwell, 1994.

SCHERRE, Maria Marta Pereira. Reanálise da concordância nominal em português. Rio de Janeiro, UFRJ, 1988. Tese de Doutorado.

- A concordância de número nos predicativos e particípios passivos. In: Organon, Porto Alegre, n. 18, pp. 52-70,1991.

SILVA, Giselle Machline de Oliveira \& SCHERRE, Maria Marta Pereira, (Org.). Padrões sociolingüísticos - análise de fenômenos variáveis do português falado na cidade do Rio de Janeiro. Rio de Janeiro, Tempo Brasileiro, Departamento de Lingüística e Filologia, UFRJ, 1996.

VAZZATA- DIAS, Juçá Fialho. A concordância de número nos predicativos e particípios passivos na fala da Região Sul: um estudo variacionista. Florianópolis, UFSC, 1996. Dissertação de Mestrado.

. A concordância de número nos predicativos/particípios passivos na fala do sul do Brasil - motivações extralingüísticas. Letras de Hoje, Porto Alegre, v. 35, n. 1, p. 209-28, mar. 2000. 
WEINREICH, U. LABOV, W, and HERZOG, M. Empirical foundations for a theory of language change. In: LEHMANN, W. P. and MALKIEL, Y. (eds.) Directions for historical linguistics. Austin, University of Texas Press, 1968. 